\title{
Civic Cooperation, Pro-Environment Attitudes, and Individual Behavior
}

\author{
Ann L. Owen \\ aowen@hamilton.edu \\ Julio Videras* \\ jvideras@,hamilton.edu \\ Hamilton College
}

*Corresponding author. 198 College Hill Road, Clinton, NY 13323. Phone: 315-859-4528, fax: 315-859-4477. We thank Tako Kato, Jennifer Thacher, Robert Turner, Steven Wu, and participants in the CU Environmental and Resource Economics Workshop and the HamiltonColgate seminars for helpful comments. 


\title{
Civic Cooperation, Pro-Environment Attitudes, and Individual Behavior
}

\begin{abstract}
Using data from approximately 30,000 individuals in over 30 countries, we find evidence that an individual's pro-environment attitudes are positively associated with her level of civic cooperation. The relationship between civic cooperation and actual behavior is more complex. Civic cooperation increases the probability of belonging to or volunteering for an environmental group, but only among those individuals who have a high level of trust in these groups. Furthermore, the influence of civic cooperation on environmental attitudes and behaviors varies with the level of development and the environmental quality of the country in which an individual lives. Finally, we document a positive relationship between pro-environment attitudes and behavior, although pro-environment attitudes are much more prevalent world-wide than pro-environment behavior.

Keywords: Civic Cooperation; Public Goods; Environmental Preferences; Environmental

Organizations
\end{abstract}




\section{Introduction}

The classic treatment of public goods highlights the lack of incentives for self-interested individuals to disclose their willingness to pay and to contribute voluntarily to the provision of public goods. Individuals' incentives are presumably linked to adherence to norms of civic behavior that encourage cooperation and collective action. In this paper, using individual-level data from over 30 different countries, we provide empirical evidence for this idea: an individual's level of civic cooperation is related to environmental preferences and the voluntary provision of environmental protection. We show that the influence of civic cooperation on environmental attitudes and behavior varies with a country's environmental quality and level of development. We also find that the impact of civic cooperation on environmental behavior is influenced by the level of trust individuals have in environmental groups. Finally, we document a positive relationship between pro-environment attitudes and behavior, although pro-environment attitudes are much more prevalent world-wide than pro-environment behavior.

There are several mechanisms through which civic cooperation can influence support for environmental protection. People who value the natural environment and disapprove of free-riding behavior in general will be more likely to disclose their preferences, support increases in taxes to provide environmental protection, and belong to environmental organizations. Civic cooperation can also alleviate the problem of the commons. Pretty and Ward (2001) present evidence from case studies showing social norms can help prevent the degradation of natural resources. Similarly, Katz (2000) shows that, lacking enforceable property rights, social capital can solve market failures in common property resources. Civic cooperation can also be a source of informal 
enforcement: individuals are more likely to "monitor" polluters and complain about perceived violations the more they disapprove of free-riders. ${ }^{1}$

In what follows, we use the World Values Survey to construct an index of civic cooperation for approximately 30,000 individuals in over 30 countries and examine whether disapproval of free-riding behavior is related to pro-environment attitudes and influences the likelihood of belonging to or volunteering unpaid work for environmental organizations. $^{2}$ We exploit the panel nature of the data by estimating country-specific effects and examining how the relationship between civic cooperation and environmental attitudes and behavior at the individual level are influenced by country characteristics. Our study differs from previous work in that the scope of the data that we analyze allows us to draw more general conclusions and also allows us to form more sophisticated hypotheses about the interaction of individual qualities and societal characteristics.

Our results improve the understanding of the determinants of demand for environmental quality and have implications for environmental policy-making in developing countries and industrialized societies. A community's or society's degree of civic cooperation can have important consequences for the development, implementation, and outcome of environmental policies. For example, in transitional economies and developing countries, the success of technology transfers depends crucially on overcoming institutional and cultural hurdles through environmental education and activism (Economy, 2004). Similarly, although public participation in environmental decision-making is increasingly common in industrialized economies, valuable and

1 For more on the role of community characteristics in informal enforcement see Blackman (1998), Pretty and Ward (2001), and Pargal and Wheeler (1996).

2 The World Values Survey is conducted on national samples (of at least 1,000 individuals) in about 80 countries. The survey asks respondents about a vast array of values, beliefs, and behaviors. 
effective decisions require motivated and well informed participants (Beierle and Cayford, 2002).

Although we find that an individual's level of civic cooperation is related to environmental preferences and the voluntary provision of environmental protection, our results also suggest that we may not always be able to count on civic cooperation to improve environmental quality. Country-level macroeconomic conditions influence the attitudes and behavior of civic-minded individuals and civic cooperation does not always translate into greater participation in environmental groups when individuals have low levels of trust in these groups. Thus, although in some circumstances policy makers may be able to rely on individuals and the environmental movement to act with less government intervention, in other circumstances a more top-down and heavy-handed approach may be more effective. Finally, this research also has methodological implications for environmental valuation research. If civic cooperation is a source of heterogeneity that explains environmental preferences and the voluntary provision of environmental protection, then questions regarding justifiable civic behavior could be used to model heterogeneous preferences and to check consistency of willingness-to-pay responses.

Our methods and results are discussed in the following five sections. Section 2 relates our paper to previous research. Section 3 presents our empirical model, Section 4 contains a discussion of our data and preliminary results, Section 5 provides our main estimation results, and Section 6 concludes. 


\section{Related Literature}

Our work is related to previous work on social norms and economic behavior. Fehr and Fischbacher (2002) make a forceful case for the importance of heterogeneity in preferences that include a concern for others, arguing that this possibility impacts the effectiveness of material incentives and the conditions for collective action. Ostrom (2000) provides a survey of theoretical and empirical research on the determinants and conditions for collective action. Ferraro, Rondeau, and Poe (2003) is an example of a public goods experiment in which participants' willingness to pay for a public environmental good depends on altruism and fair contributions.

In addition to empirical examinations of the determinants of collective action and experimental studies on the provision of public goods, there are numerous analyses of the consequences of social norms and social capital on economic growth and long-term sustainability of natural resources. For example, Knack and Keefer (1997) use the World Values Survey data to construct an aggregate index of civic norms and examine the empirical relationship between a country's economic growth and its citizens' attitudes towards free-riders. Knack and Keefer find that civic norms have a positive and statistically significant influence on growth. In the area of sustainable growth, Katz (2000) and Pretty and Ward (2001) gather evidence from case studies that indicates socially cohesive groups can manage natural resources in ways that help prevent their over-use and degradation. ${ }^{3}$

3 Sociologists have used the World Values Survey and other opinion polls to explore cross-country differences in the support for environmental protection. See, for example, Inglehart (1995) and Brechin and Kempton (1994). 
Because we allow the effects of civic cooperation to vary with country characteristics such as level of development, our work is also related to the literature on the environmental Kuznets curve. Many studies have sought evidence of the so-called environmental Kuznets curve: an inverse U-shaped relationship between pollution and income. Grossman and Krueger (1993, 1995), Shafik (1994), and Selden and Song (1994, 1995) are important seminal studies in this area. More recently, Harbaugh, Levinson, and Wilson (2002) argue that the evidence in favor of the existence of an environmental Kuznets curve is not as robust as commonly thought. Similarly, Israel and Levinson (2004) do not find a consistent pattern between income and willingness to pay to protect the environment. Israel (2004) also examines the relationship between country-level income and household support for environmental protection using the 1989 Harris survey. Dasgupta et al. (2002) and Copeland and Taylor (2004) critically examine this literature. Our work differs from the Kuznets curve literature, however, in that we focus on the interaction of country and other individual characteristics (in particular, civic cooperation) in determining environmental behavior and attitudes.

\section{Empirical Model}

In order to empirically examine the relationship between civic cooperation and environmental attitudes we estimate the following equation

$$
P\left(\text { ATTITUDE }_{i j}=1\right)=\Phi\left(\beta_{0}+\beta_{1} \text { CIVIC }_{i j}+\beta_{2} \text { POLITICAL }_{i j}+\beta_{3} \text { DEMOGRAPHICS }_{i j}+\alpha_{j}\right)
$$

where $\alpha$ is a country-specific random effect for the country $j$ in which individual $i$ lives. While we explain the remaining independent variables in more detail below, in general, ATTITUDE measures various attitudes towards environmental protection held by 
individual $i$, CIVIC is an index of civic cooperation, POLITICAL is an index measuring political activism, and DEMOGRAPHICS is a vector containing the age, gender, dummy variables for education levels, the relative place in the income distribution in that individual's country (i.e., the quintile), and a dummy variable for the size of the town in which the individual lives. In order to examine how country characteristics may affect attitudes, we also estimated Equation 1 including two different country characteristics: the level of development (the natural log of GDP per capita) and environmental quality (Energy use/GDP), interacting these variables with CIVIC. ${ }^{4}$ To study the impact of CIVIC on actual behavior, we modify equation 1 by adding a measure of environmental attitudes to the list of explanatory variables and substituting two different measures of pro-environment behavior for ATTITUDE. ${ }^{5}$ While we have multiple observations of individuals for each country, we have only one observation per individual in the time period 2000-2001. Thus, our panel is formed by having multiple observations for each country. This allows us to estimate a country-specific effect via a random effects procedure.

Country-specific data on energy use and GDP were obtained from the World Bank's World Development Indicators. All other data come from the 2000-2001 World Values Survey, a survey of individual attitudes and social behaviors conducted simultaneously in several different developed and developing countries. More detail on the data we use is provided below.

\footnotetext{
${ }^{4}$ We also used $\mathrm{CO} 2$ emissions/GDP as a measure of environmental quality and obtain qualitatively identical results. Results from these estimations or any others discussed here but not reported in the text are available from the authors upon request.

${ }^{5}$ We estimate the random effects probit models for attitudes and behavior separately. We should note that when we estimate the determinants of environmental behavior excluding attitudes, we get similar results for the remaining coefficients, suggesting that the inclusion of environmental attitudes in the behavior estimation is not biasing the coefficients of interest.
} 


\section{Measures of Environmental Attitudes and Behavior}

We consider two measures of attitudes towards the environment, willingness to pay taxes to prevent pollution (TAX), and prioritizing environmental protection over economic growth (PROTECTION). Specifically, TAX is a binary variable equal to one if the individual strongly agrees to the following statement: "I would agree to an increase in taxes if the extra money were used to prevent environmental pollution." PROTECTION is an alternative measure of environmental attitudes, equal to 1 if the individual claims that the statement "Protecting the environment should be given priority, even if it causes slower economic growth and some lost jobs" is "closer to your point of view" than the statement "Economic growth and creating jobs should be the top priority, even if the environment suffers to some extent." In the attitude model developed by Green and Tunstall (2001), PROTECTION would be considered an expression of attitudes towards environmental protection while TAX would be considered a behavioral intention, that is, an expression of intention to sacrifice income to protect the environment. Although we refer to both measures as attitudes, there are subtle differences between "pure" attitudes and behavioral intentions and it is possible that different processes determine these two variables.

One issue in using TAX to measure attitudes towards the environment is that the answer to this question combines attitudes towards the environment with attitudes towards the appropriate role of government in providing public goods. It is possible that individuals who are frequent free-riders and have low values of CIVIC might support taxes to protect the environment, not because they care more about the environment than others, but because they believe that only the government can solve a free-riding 
problem. To address this possibility we also examined a third attitudinal variable that was equal to one if the individual strongly agrees to the following statement: "I would give part of my income if I were certain that the money would be used to prevent environmental pollution." We received identical results for this variable and TAX, mitigating the concern that TAX is eliciting attitudes about appropriate roles of government and not attitudes about the environment. For the sake of brevity, we report only the results for TAX. Furthermore, TAX is comparable to variables used in previous studies such as Israel and Levinson (2004), and direct valuation surveys commonly use taxes as a payment method.

In addition to attitudes, we examine two measures of pro-environment behavior: BELONG equals one if the individual states he or she belongs to conservation, environmental, or animal rights groups; and WORK equals one if the individual states he or she is currently doing unpaid work for conservation, environmental, or animal rights groups. Although false reporting can be a problem with self-reported measures, descriptive statistics show the rate of respondents who belong to environmental groups or who do unpaid work is low, mitigating the concern about this issue. Furthermore, the World Values Survey asks these questions only where there are such conservation, animal rights, and environmental groups. Data limitations restrict us to examining only these two behaviors that are specific to joining or volunteering for an environmental group. While examining this behavior is interesting, we should point out that it is a relatively narrow definition of pro-environment behavior. Individuals who care about the environment and who are civic-minded may choose to exhibit other, more individualistic, pro-environment behaviors that we do not observe (e.g., recycling, energy conservation). 


\section{Measures of Civic Cooperation and Political Activism}

We create an index of civic cooperation, CIVIC, that captures attitudes towards freeriding behavior. We follow Knack and Keefer (1997) who use data from the World Values Survey to formulate an indicator of civic cooperation by adding responses to questions regarding whether certain free-riding behaviors can ever be justified. Specifically, for each of the following four free-riding behaviors, we add a 1 to CIVIC each time the respondent states that behavior is never justifiable. The behaviors examined are: (i) "Claiming government benefits to which you are not entitled;" (ii) "Avoiding a fare on public transport;" (iii) "Cheating on taxes if you have a chance;" and (iv) "Someone accepting a bribe in the course of their duties." Thus, CIVIC takes on values of 0 to 4 , with 4 being associated with the highest levels of civic cooperation. If civic cooperation is associated with the viability of providing voluntarily public goods, then CIVIC should be positively related to pro-environment attitudes and behavior, everything else equal.

Although CIVIC explicitly examines attitudes about free-riding behavior, political activism may also be related to civic cooperation and to environmental attitudes and behavior. Therefore, we also construct an index of political engagement and examine how it influences attitudes and behavior towards the environment. To control for an individual's political activism, we construct an index by adding 1 if the individual has ever (i) signed a petition, (ii) joined in boycotts, (iii) attended lawful demonstrations, (iv) joined unofficial strikes, and (v) occupied buildings or factories. Thus, the index POLITICAL can take on the values 0 to 5 , with five indicating the highest level of political activism. 


\section{Demographics}

Basic demographic factors are generally thought to be determinants of environmental preferences, and we control for these as well because they are possibly also related to civic cooperation. We include the respondent's age, AGE; the respondent's gender: MALE equals 1 if the respondent is male; and income categories. We construct five categorical variables for each income quintile group, from INCOME1 that equals 1 if the respondent's household income is in the bottom income quintile within their country to INCOME5 that equals 1 if the respondent's household income is in the country's top income quintile. In the regressions, we exclude the fifth quintile so that estimates of income categories are interpreted relative to the richest group in each country. Similarly, we include the respondent's education. There are eight categorical variables from EDUCATION1 equal to 1 if the individual has no formal education to EDUCATION8 equal to 1 if the individual has university-level education. In the regressions, we exclude individuals with no formal education so that estimates are interpreted relative to the least educated group. Finally, we include dummy variables for the size of the town in which an individual lives because living in an urban vs. rural areas affect the benefits derived from environmental protection.

\section{Country-Specific Factors}

Although we include a country-specific effect in equation 1, we are still interested in examining the role that a country's environmental quality may play in determining individual's attitudes and behavior. We use energy per GDP as a proxy for environmental quality: ENERGY is average kilograms of oil-equivalent energy use per 
dollar of GDP (or energy intensity) for the period 1995-1999. We divide energy use by GDP because energy use is highly correlated with a country's level of development. High values of ENERGY indicates that a country has a high energy use, given its level of economic activity. In other words, high values may indicate that environmental quality is worse than would be expected, given the level of GDP. An alternative specification would be to have absolute measures of environmental quality and GDP enter the equation as separate variables. However, these variables are highly correlated and introducing them both simultaneously creates multicollinearity. ${ }^{6}$ In order to allow for a nonlinear relationship between a country's proxies for environmental quality and attitudes and behavior we also include quadratic terms for average energy intensity. (We also substituted $\mathrm{CO} 2$ emissions/GDP for ENERGY in all our estimations. These measures are highly correlated and we received qualitatively identical results.)

Finally, we also estimate additional models that include a country's per capita GDP (measured in 1995 dollars adjusted for purchasing power parity) to gain insight into the influence of economic development on attitudes and behaviors. Because the distribution of GDP is positively skewed, we transform the explanatory variable taking the natural log of average GDP for the period 1995-1999. As Katz (2000) and Pretty and Ward (2001) have suggested, civic norms can be particularly relevant for communities or countries that lack formal institutions that can provide the desired level of environmental support. Thus, we might expect the marginal effect of CIVIC on attitudes and behaviors to vary across countries. For example, civic-minded individuals might participate more often and actively in supporting the environment in poor countries where public 
institutions cannot provide environmental protection than in rich countries where relatively extensive environmental regulations are in place. On the other hand, civicminded individuals in developing countries might weigh aggregate income growth more heavily than environmental protection.

\section{Data and preliminary analyses}

In total, we have data for a maximum of 36 countries that include a range of industrialized and less developed countries. (See Appendix for a list of countries.) Descriptive statistics for the entire sample are presented in Table 1. Some proenvironment attitudes are prevalent in the sample, with more than half of the respondents agreeing that protecting the environment should be given priority over economic growth (PROTECTION). However, the percent of respondents supporting taxes to improve the environment (TAX) is smaller at 14 percent. Pro-environment behavior is even less apparent with only 7 percent belonging to an environmental group (BELONG) and only 4 percent of the respondents doing unpaid work for environmental causes (WORK). Many of the individuals who report doing unpaid work also belong to an environmental group, with three percent of the respondents self-reporting both behaviors. Thus, about 8 percent of the total sample exhibits one or both these pro-environment behaviors.

Attitudes and behaviors vary with GDP in an interesting way. To examine this pattern, we split the sample in half and compare the proportions of individuals that exhibit these attitudes and behaviors in high and low income countries. The results are reported in Table 2. Interestingly, individuals in low income countries seem to be more likely to support taxes to protect the environment, but are less likely to belong to

and GDP is .84 . 
environmental groups. (Recall that these questions are only asked in countries in which environmental groups exist.) We do not find any strong statistical evidence that the priority that individuals assign to environmental protection relative to economic growth varies between high and low income countries, but the proportion of individuals in low income countries who belong to environmental groups is 2 percent lower than the proportion in high income countries. Interestingly, more respondents in low income countries do unpaid work for environmental groups than respondents in high income countries. The difference is statistically significant and, given a sample average of 4 percent, economically meaningful: 2.2 percent. These differences in environmental behavior between high and low income countries can be due to differences in the shadow price of labor and the ability to contribute monetarily to environmental groups.

The sample average of the index of civic cooperation, CIVIC, is 2.5 and the standard deviation is 1.47 . Accepting bribes is the behavior most people ( 75 percent in the sample) strongly believe is unjustifiable. Approximately 62 percent strongly agree cheating on taxes is unjustifiable; 60 percent of respondents strongly agree that falsely claiming benefits is unjustifiable, while about 58 percent believe not paying the fare in public transportation is unjustifiable. The correlation between CIVIC and GDP is negative and small, -.05 . CIVIC is also negatively correlated with energy intensity: the correlation coefficient is -.08 .

On average, respondents do not engage in political activism. The sample mean of the index POLITICAL is only .78. CIVIC and POLITICAL have a small and negative correlation coefficient: -.05 . Respondents in richer countries seem to be more politically active, the correlation coefficient between POLITICAL and GDP is .29. POLITICAL is 
weakly negatively correlated with energy intensity (oil-equivalent kilograms per \$ GDP): the correlation coefficient is -.082 .

\section{Results}

The results of estimating equation 1 appear in Table 3. The first two columns of Table 3 show the determinants of environmental attitudes and the last two columns explain environmental behavior. In this initial set of estimations, we find evidence for the expected relationship between civic cooperation and environmental attitudes. In the first two columns of Table 3, the coefficient on CIVIC is positive and significant, however, we are unable to draw the same conclusions regarding civic cooperation and behavior from these basic models. We discuss this somewhat unexpected result in more depth later, but first we discuss some of the more straightforward results of our estimations.

While the relationship between civic cooperation and pro-environment attitudes and behaviors is the main focus of this paper, before delving into this relationship further, we point out a number of other findings that generally hold across specifications. First, the index of political activism is a significant predictor of attitudes and behaviors. The marginal effect of POLITICAL in the response probability of supporting higher taxes is a 2.5 percent increase. The marginal effect in PROTECTION is 3.5 percent while the effects in the two environmental behavior variables are smaller (about a 1 percentage point increase in the probability of either behavior). Hence, political activism has a slightly larger impact on the likelihood that respondents will state they support environmental protection than on the likelihood that respondents actually sacrifice their time and money to provide environmental protection. 
Individuals with more education are more likely to state and actually support environmental protection than individuals with low levels of education. The size of town also influences attitudes and behaviors. Respondents who live in big cities are more likely to support environmental protection than individuals living in small towns. Age is generally not a significant predictor of attitudes after controlling for other demographic characteristics, however, older individuals are more likely to belong to environmental groups. Finally, we also conclude that low income individuals are less likely to have proenvironment attitudes or behavior: estimates of income categorical variables indicate that respondents in the second and third income quintiles are in general less likely to support environmental protection than respondents in the fourth and fifth income quintiles.

Although we have included a country-specific random effect in the estimations in Table 3, the characteristics of the countries in our sample vary a great deal and we further explore the relationship between civic cooperation and environmental attitudes and behavior by examining how a country's characteristics such as level of development and environmental quality influence individuals both directly and indirectly by impacting the effect of civic cooperation. Although a full set of estimated coefficients for each specification appears in tables in the appendix, we focus our discussion by examining the marginal effects of CIVIC on attitudes and behavior and how the marginal effects change after controlling for country-specific characteristics. We should note that we estimate the impact of a country's environmental quality on individual attitudes and behavior, not aggregate attitudes. Were we to attempt to analyze the impact of country environmental quality on average attitudes and behavior in a country, the direction of causality would be unclear (even though we use a lagged value of environmental quality). In interpreting 
our individual-level estimations, we assume that the attitudes and behavior of any one individual cannot affect the overall environmental quality of the country.

To discuss the influence of CIVIC and country characteristics, we summarize their marginal effects on the response probability. Let $X b$ be the vector of explanatory variables and estimated coefficients and $y$ be the dependent variable, then the estimated partial effect of $x_{j}$ on the response probability is: $\frac{\partial P(y=1 \mid X)}{\partial x_{j}}=g(X b) \frac{\partial(X b)}{\partial x_{j}}$, where $g(X b)$ is the density function of the normal distribution. Note that $g(X b)$ is strictly positive and therefore the sign of the marginal effect is equal to the sign of the effect on the linear prediction $\frac{\partial(X b)}{\partial x_{j}}$. In particular we are interested in the marginal effects of CIVIC and country characteristics on attitudes and behaviors ${ }^{7}$. Table 4 summarizes the marginal effects of CIVIC. In Table 4, we show the mean of the individual marginal effects, however, evaluating the marginal effects at the mean for each variable yields similar results. In what follows, we discuss these results, first by exploring the relationship between pro-environment attitudes, civic cooperation and country characteristics. Later, we discuss pro-environment behaviors.

\subsection{Pro-Environment Attitudes}

Table 4 summarizes the marginal effects of CIVIC, GDP, and energy intensity on attitudes. In the base specification reported in Table 4 (Panel A), CIVIC enters the estimation separately with no interaction terms (this is the specification reported in Table

7 Because the unobserved country-effects are not estimated in a random effects probit models, $\mathrm{g}(X b)$ can only be calculated assuming the unobserved country-effects are zero. While a different assumption may 
3). Each of the other two specifications add a country characteristic and the interaction of that characteristic with CIVIC. Specifically, Panel B adds GDP and GDP*CIVIC, and Panel $\mathrm{C}$ adds ENERGY, ENERGY ${ }^{2}$, ENERGY*CIVIC, and ENERGY ${ }^{2 *}$ CIVIC $^{8}$ (See Appendix Table 1 for a full set of estimated coefficients associated with Panel B and Appendix Table 2 for the coefficients associated with Panel C.)

Broadly speaking, these results confirm our earlier conclusion that civic-minded individuals are more likely to state they support environmental protection; the partial effects of CIVIC vary across specifications with estimated values between a 1.3 and a 1.9 percentage point increase in the response probability. In the three specifications examining attitudes towards environmental taxes, none of the interaction terms between CIVIC and country characteristics were significant, indicating that we find no evidence that the effect of being civic-minded on stated willingness to pay environmental taxes varies with country characteristics. (Note that the statistically significant coefficients are in bold in Tables 4 and 5.) $)^{9}$

In contrast, the partial effects of CIVIC on the response probability of PROTECTION do depend on observable country characteristics. Although at higher levels of income all individuals are more willing to sacrifice further economic growth to obtain greater environmental protection, high levels of civic cooperation are more

change the magnitude of the marginal effect, it would not change the sign or the relative effect of any two variables.

${ }^{8}$ Although initially we estimated the models without the square term of ENERGY and its interaction with CIVIC, we found that in the models explaining behavior (discussed later and reported in Table 5) the coefficients of the interaction of ENERGY and CIVIC were negative and statistically significant. Because a monotonically decreasing marginal effect on the probability of engaging in pro-environment behavior with respect to energy use is counterintuitive, we include a non-linear effect due to the possibility that the unexpected relationship was due to misspecification. As expected, the estimated coefficient of the interaction between the square term of ENERGY and CIVIC is positive and statistically significant. For symmetry, we estimate attitudes assuming a non-linear specification. 
important in determining support for environmental protection vs. economic growth in low income countries than in high income countries. These results support the idea that at low levels of income the marginal utility of economic growth is greater, therefore, being civic-minded is much more crucial in determining this preference.

We also find interesting results in examining how the marginal effects of CIVIC depend on environmental quality in the PROTECTION estimation. Specifically, our estimation results suggest that the impact of civic cooperation is greater when ENERGY is high (or environmental quality is relatively low.) This finding implies that when environmental quality is lower than should be expected given the level of economic activity, individuals have a greater concern for the environment. The fact that the marginal effect of CIVIC on this attitude is even greater when environmental quality is low suggests that this concern for the environment is amplified among civic-minded individuals.

We also examine the marginal effects of the country characteristics. We find that the marginal effect of GDP in determining the willingness to pay higher taxes (TAX) is statistically insignificant. However, the marginal effect of energy intensity on willingness to pay higher taxes (TAX) is negative and relatively large: the marginal effect of ENERGY in the TAX estimation is a 27 percent decrease in the response probability. This implies that a one standard deviation increase in ENERGY (.19), translates into a 5 percentage point decrease in the probability of support for environmental taxes. These effects are relatively large, given that only 14 percent of the sample strongly supported environmental taxes.

\footnotetext{
${ }^{9}$ However, as indicated in Table 4, we must include the insignificant coefficients on these interactions in calculating the marginal effect of CIVIC.
} 
The effects of country characteristics are reversed when we examine the probability of support for the environment relative to economic growth (PROTECTION). Now an increase in GDP or ENERGY is associated with a greater probability that individuals support environmental protection over economic growth. The marginal effects reported in Table 4 indicate that a one standard deviation increase in ENERGY yields a 6.4 percentage point increase in the response probability.

These findings suggest several interesting conclusions. First, individuals respond to questions about their overall environmental preferences (environmental protection versus economic growth) differently than they respond to more specific questions that elicit their willingness to sacrifice income to support the environment (higher taxes). Hence, there is evidence that the distinction between attitudes and behavioral intentions, as in the model developed by Green and Tunstall (2001), is empirically relevant. Second, as GDP increases, individuals seem more willing to sacrifice income to obtain environmental protection, consistent with a decreasing marginal utility of income. In addition, high levels of civic cooperation are more important in determining support for environmental protection vs. economic growth in low income countries than in high income countries. Finally, individuals are also sensitive to the current balance between GDP and environmental quality when making the tradeoff between growth and environmental protection-if current environmental quality indicators suggest that environmental quality is low for the level of GDP, individuals appear to be expressing opinions consistent with getting environmental quality back in line. It is somewhat difficult to explain the negative marginal effect of ENERGY in determining the probability that individuals say they are willing to pay taxes for environmental protection. 
Perhaps, this behavior could be rationalized if the perceived taxes needed to protect the environment are much higher when environmental quality is lower. Thus, individuals in countries with high levels of ENERGY may believe that the tax burden associated with environmental improvement is too high and they are unwilling to pay it.

\subsection{Pro-Environment Behaviors}

We now examine pro-environment behavior in a manner parallel to our examination of attitudes. The structure of Table 5 mimics that of Table 4, except we now look at the marginal effects of CIVIC, GDP, ENERGY and TAX on the probability of belonging to an environmental group (BELONG) or doing unpaid work for an environmental cause (WORK). ${ }^{10}$ These results allow us to consider two important issues. First, are attitudes and behavior related? Second, how does civic cooperation affect environmental behavior, after we control for environmental attitudes? In this section, we address these questions in this order.

\section{The Effects of Attitudes on Behaviors}

Attitudes and behaviors are not necessarily congruent. If people's stated willingness to pay higher taxes and preference for environmental protection versus economic growth truly reflect their environmental preferences then we should expect these attitudes to have a positive and statistically significant effect on the pro-environment behavior. The marginal effects of TAX in all of our behavior estimations that are reported in Table 5 do in fact show this result. (A full set of results is presented in Appendix Tables 1 and 2.)

\footnotetext{
${ }^{10}$ In the tables, we report the results using only TAX as the measure of environmental attitudes. We obtain similar results when we use PROTECTION.
} 
These results indicate that individuals who are willing to pay taxes to protect the environment are also more likely to belong to an environmental group and to do unpaid work for an environmental group. Given the relatively small percentage of people who engage in these behaviors, the effects are rather large: the marginal effect of TAX is an increase in the probability of belonging to an environmental group of between 3.3 and 3.7 percentage points. The marginal effect of TAX on the probability of doing unpaid work for an environmental group is slightly smaller, between a 2.1 and 2.5 percentage point increase.

The finding that preferences and behavioral intentions are strongly significant predictors of behaviors in such a wide sample of individuals and countries could help practitioners of direct valuation methods to defend their use of elicitation technique and also to argue that general statements about environmental support are correlated with actual behavior.

\section{Civic Cooperation and Environmental Behavior}

Of course, the fact that CIVIC is positively related to attitudes and attitudes are positively related to behavior does suggest that civic cooperation plays at least an indirect role in the determination of behavior. In Table 5, however, we also explore whether there is an independent effect of CIVC on behavior. In other words, are civic-minded people more likely to belong to or volunteer for environmental groups, even after controlling for environmental attitudes? ${ }^{11}$ Our initial estimates indicate that the relationship between CIVIC and behaviors is more complex than the relationship between CIVIC and

\footnotetext{
${ }^{11}$ One might also think that there should be an interaction between CIVIC and attitudes in determining behavior, however, adding this interaction term to our specification yields statistically insignificant results.
} 
attitudes/intentions. As we noted earlier, in the base specification that does not control for environmental quality or GDP, the marginal effect of CIVIC on behaviors is statistically insignificant and the same is true for the specification that includes GDP. However, once we control for environmental quality, CIVIC enters the estimations with statistically significant marginal effects. Although the mean of the individual marginal effects of CIVIC in the model that includes ENERGY is small and positive (Panel C of Table 5), the median is virtually 0 , with roughly half the sample having negative marginal effects for CIVIC and half the sample having positive marginal effects. The non-linearity in the marginal effects indicates that at either high or low levels of energy use, higher values of CIVIC result in high probabilities of belonging to or volunteering for environmental groups. At intermediate values of ENERGY, the marginal effect of CIVIC is negative. ${ }^{12}$

The fact that the marginal effects of CIVIC on the probability of engaging in these pro-environment behaviors are negative for some individuals in the sample is somewhat puzzling. However, we should point out that our measures of pro-environment behavior only consider activities carried out with environmental groups. Because people's ability to contribute to environmental protection, either with time or money, is limited, those individuals who are civic-minded and believe contributing to environmental groups is not an effective way to improve environmental quality may engage in other pro-environment behaviors that do not involve these groups and that we do not observe. Thus, a factor that

\footnotetext{
${ }^{12}$ In order to determine if these results are overly-influenced by countries with high levels of energy intensity, we drop respondents from countries in the $95^{\text {th }}$ percentile of the distributions of energy intensity. The results are qualitatively identical, very similar quantitatively and there are no differences in statistical significance. Thus, we conclude that these results are not being driven by a few outlier countries. We should also note that by estimating random effects probit models we control for unobservable country
} 
is likely to influence individuals' incentives to belong to an environmental group is their level of trust in these organizations. To follow up on this hypothesis, we utilize the answer to an additional question in the World Values Survey that is asked in only about one-third of our sample (around 12,000 individuals): “..how much confidence do you have in....The Environmental Protection Movement.” We use the answer to this question to form an ordinal variable, from 0 to 3 , with 0 indicating "None at all" and 3 indicating "A great deal." We include this variable, TRUST, in the estimation of pro-environment behaviors, having it enter by itself and interacted with CIVIC. The results of this estimation appear in Table $6 .{ }^{13}$

Now, after controlling for trust in the environmental movement, CIVIC has the expected positive marginal effect for those individuals who trust the environmental movement "A great deal." 14 These new results allow us to draw a sensible conclusion: individuals with high levels of civic cooperation are more likely to engage in activities associated with environmental groups if they trust these groups. ${ }^{15}$

We obtain similar results for TRUST and its interaction with CIVIC in the specifications that also control for GDP and ENERGY (See Appendix Table 3 for the full set of coefficients.) It is interesting that the marginal effects of CIVIC on behavior still depends non-linearly on ENERGY, suggesting that CIVIC cooperation is most important

characteristics, and we, therefore, do not believe emissions or energy intensity proxy for some important omitted variable.

${ }^{13}$ Results in Table 6 are from estimations on a much smaller sample. We did confirm that the qualitative conclusions drawn from results reported earlier in the paper (i.e. results in Tables 4 and 5) hold even using this smaller sample.

${ }^{14}$ Appendix Table 3 shows the same results when TRUST is included in the specifications that incorporate GDP and energy intensity. The non-linear relationship between behaviors and CIVIC is unaffected by the presence of TRUST.

${ }^{15}$ Overall, higher values of CIVIC are positively related to membership in many different kinds of social and political action groups that are mentioned in the World Values Survey (e.g., human rights groups, women's movement, labor unions, religious organizations, etc.). 
in determining environmental behavior when environmental quality is either particularly high or low. This might be the case if, in general, individuals have few incentives to take action when environmental quality is either relatively good or bad because they doubt contributing to environmental groups can then have a significant beneficial impact on environmental quality. When environmental quality is poor, the doubt may stem from the size of the task, and when environmental quality is relatively good, individuals may believe that their effort will produce relatively small marginal gains. Under these circumstances, civic cooperation may be particularly important in determining proenvironment behavior. Although we cannot provide direct evidence on this hypothesis, we do have confidence in the specification that includes trust in the environmental movement: after controlling for TRUST, less than 10 percent of our sample retains the negative marginal effect of CIVIC on behavior.

Finally, we briefly address the impact of GDP and ENERGY on environmental behaviors. The results in Panels $\mathrm{B}$ and $\mathrm{C}$ of Table 5 indicate that both GDP and ENERGY have negative marginal effects on BELONG and WORK. The negative effect of GDP on environmental behaviors could be a result of respondents in industrialized countries being wary of how further environmental protection would affect their current standard of living. For example, in the USA, economic, demographic, and cultural trends (such as the popularity of sport utility vehicles) are behind increases in consumption of energy and carbon dioxide emissions (Darmstadter, 2001). Using data from the 1989 Harris survey, Israel (2004) finds a similar negative relationship between per capita income and support for environmental protection. The negative effect of ENERGY is harder to rationalize; it implies that when environmental quality is lower, individuals are 
less likely to belong to or volunteer for environmental groups. However, our results are consistent with individuals in low environmental quality countries placing less value on their contribution to environmental groups. In other words, as environmental quality worsens, people may feel that their individual efforts will be less productive in producing the desired environmental benefits.

\section{Conclusion}

In this paper, we have explored the determinants of pro-environment behavior and attitudes, with a focus on the effect of civic cooperation. As might be expected, in general we find that civic cooperation is associated with pro-environment attitudes. We also document a positive relationship between pro-environment attitudes and behavior. We find that the relationship between civic cooperation and actual behavior is complex. The influence of civic cooperation on the likelihood of belonging to or volunteering for environmental organizations depends on the trust individuals have in these organizations. Individuals who have greater trust in the environmental movement are more likely to engage in pro-environment behavior and this effect is particularly strong for people with high levels of civic cooperation.

Country characteristics also matter in determining pro-environment behavior and attitudes. Higher GDP is likely to be associated with a higher value put on the environment relative to further income growth, however, it is associated with lower probabilities of pro-environment behavior. Individuals in countries with poor environmental quality are less likely to be willing to pay taxes to improve the 
environment or to belong to or volunteer for environmental groups, even though they value increases in environmental quality over further income growth.

Our results are important because they provide empirical evidence on the link between civic cooperation and the private provision of a public good (i.e., environmental quality). Because we use individual level data from over 30 countries, our results about this relationship are very general. In addition, the fact that civic cooperation may be more or less effective in generating pro-environment behaviors and attitudes depending on the level of trust in the environmental movement and country characteristics may be useful for the design and implementation of environmental policies. Although in the literature on social norms and the environment there is evidence that the degree of civic cooperation influences the support for environmental protection, our results suggest that the benefits of civic cooperation might not always be evident: trust in the environmental movement and country-level macroeconomic conditions influence the incentives of civicminded individuals to contribute to environmental protection. Thus, in some circumstances, policy makers who seek to improve environmental quality may be more able to rely on individuals and social movements to act with less government intervention, while in other circumstances, a more top-down and heavy-handed approach may be more effective. 


\section{References}

Beierle, Thomas C., and Cayford, Jerry (2002): Democracy in Practice: Public Participation in Environmental Decisions. Washington, DC: Resources for the Future.

Blackman, Allan (1998): "Community pressure and clean technology in the informal sector: An econometric analysis of the adoption of propane by traditional Mexican brickmakers," Journal of Environmental Economics and Management, 35(1): 1-21.

Brechin, Steven R., and Kempton, William (1994): "Global environmentalism: A challenge to the postmaterialism thesis?” Social Science Quarterly 75:245-269.

Copeland, Brian R., and Taylor, M. Scott (2004): “Trade, Growth, and the Environment," Journal of Economic Literature, XLII(1): 7-71.

Darmstadter, Joel (2001): "The Energy-CO2 Connection. A Review of Trends and Challenges," in Climate Change Economics and Policy, Michael E. Toman, editor. Resources for the Future, Washington, DC.

Dasgupta, Susmita, Laplante, Benoit, Wang, Hua, and Wheeler, David (2002): "Confronting the Environmental Kuznets Curve,” Journal of Economic Perspectives, 16(1): 147-168.

Economy, Elizabeth, E. (2004): The River Runs Black: The Environmental Challenge to China's Future. Ithaca \& London: Cornell University Press.

Fehr, Ernst and Fischbacher, Urs (2002): "Why Social Preferences Matter: The Impact of Nonselfish Motives on Competition, Cooperation and Incentives." Economic Journal, 112(478): C1C33.

Ferraro, Paul, J.; Rondeau, Daniel; Poe, Gregory, L. (2003): "Detecting Other-Regarding Behavior with Virtual Players." Journal of Economic Behavior and Organization, 51(1): 99-109.

Green, Colin, and Sylvia Tunstall (2001): “A Psychological Perspective," in Valuing Environmental Preferences, Ian J. Bateman and Kenneth G. Willis, editors. Oxford University Press.

Grossman Gene M., and Krueger, Alan B. (1993): "Environmental Impacts of a North American Free Trade Agreement," in The U.S.-Mexico Free Trade Agreements, Peter Garber (editor), Cambridge MA, MIT Press.

Grossman Gene M., and Krueger, Alan B. (1995): "Economic Growth and the Environment." Quarterly Journal of Economics, 110: 353-377.

Harbaugh, William T., Levinson, Arik, and Wilson, David Molloy (2002): "Reexamining the Empirical Evidence for an Environmental Kuznets Curve." Review of Economics and Statistics, 84: 541-551.

Inglehart, Ronald (1995): "Public support for environmental protection: Objective problems and subjective values in 43 societies." PS: Political Science \& Politics, 28:57-72. 
Israel, Debra (2004): “International Support for Environmental Protection.” Environment and Development Economics, 9(6), in press.

Israel, Debra, and Levinson, Arik (2004): "Willingness to Pay for Environmental Quality: Testable Empirical Implications of the Growth and Environmental Literature." Contributions to Economic Analysis and Policy, 1st Quarter 2004; 3(1): 1-29

Katz, Elizabeth G. (2000): "Social capital and natural capital: A comparative analysis of land tenure and natural resource management in Guatemala," Land Economics, 76(1): 114-132.

Knack, Stephen; and Keefer, Philip (1997): "Does Social Capital Have an Economic Payoff? A Cross-Country Investigation,” Quarterly Journal of Economics, 112(4):1251-1288.

Ostrom, Elinor (2000): "Collective Action and the Evolution of Social Norms." Journal of Economic Perspectives, 14(3): 137-158.

Pargal, S., and D. Wheeler (1996): "Informal regulation of industrial pollution in developing countries: Evidence from Indonesia," Journal of Political Economy, 104(6): 1314-.

Pretty, Jules, and Hugh Ward (2001): "Social Capital and the Environment," World Development, 29(2), 209-227.

Selden, Thomas, and Daqing Song (1994): "Environmental Quality and Development: Is There a Kuznets Curve for Air Pollution Emissions?" Journal of Environmental Economics and Management, 27: 147-162.

Selden, Thomas, and Daqing Song (1995): "Neoclassical Growth, the J Curve for Abatement, and the Inverted U Curve for Pollution," Journal of Environmental Economics and Management, 29: 162-168.

Shafik, Nemat (1994): "Economic Development and Environmental Quality: An Econometric Analysis," Oxford Economic Papers, 46: 757-773. 
Table 1: Descriptive Statistics

\begin{tabular}{|c|c|c|c|c|c|}
\hline Variable & Description & Countries & Observations & Mean & Std. Dev. \\
\hline TAX & $\begin{array}{l}=1 \text { if willing to pay higher taxes to } \\
\text { support environmental protection }\end{array}$ & 33 & 29500 & .140 & .348 \\
\hline PROTECTION & $\begin{array}{l}=1 \text { if priority is environmental } \\
\text { protection over economic growth }\end{array}$ & 24 & 23207 & .504 & .499 \\
\hline BELONG & $\begin{array}{c}=1 \text { if belong to environmental } \\
\text { organization }\end{array}$ & 36 & 33041 & .073 & .261 \\
\hline WORK & $\begin{array}{c}=1 \text { if do unpaid work for environmental } \\
\text { organization }\end{array}$ & 34 & 31482 & .041 & .197 \\
\hline Age & Age & 36 & 33041 & 42.96 & 16.32 \\
\hline Male & $=1$ if male & 36 & 33041 & .485 & .499 \\
\hline POLITICAL & $\begin{array}{c}0-5 \text { scale of involvement in political } \\
\text { activities }\end{array}$ & 36 & 33041 & .784 & 1.073 \\
\hline CIVIC & $0-4$ scale of civic behavior & 36 & 33041 & 2.50 & 1.47 \\
\hline TRUST & $\begin{array}{l}0-3 \text { scale of trust in environmental } \\
\text { movement }\end{array}$ & 16 & 12724 & 1.71 & .871 \\
\hline GDP & $\begin{array}{l}\text { Natural log of GDP (\$1995 purchasing } \\
\text { power parity adjusted), average 1995-99 }\end{array}$ & 33 & 29327 & 9.19 & .993 \\
\hline ENERGY & $\begin{array}{l}\text { Energy Intensity }=\mathrm{kg} \text { oil-equivalent } \\
\text { energy use per GDP, average 1995-99 }\end{array}$ & 33 & 29327 & .287 & .184 \\
\hline Educ1 & $=1$ if no formal education & 36 & 33041 & .083 & .276 \\
\hline Educ2 & $=1$ incomplete primary education & 36 & 33041 & .152 & .356 \\
\hline Educ3 & $=1$ complete primary education & 36 & 33041 & .102 & .302 \\
\hline Educ4 & $\begin{array}{l}=1 \text { if incomplete secondary education } \\
\text { (technical/vocational) }\end{array}$ & 36 & 33041 & .149 & .357 \\
\hline Educ5 & $\begin{array}{c}=1 \text { if complete secondary education } \\
\text { (technical/vocational) }\end{array}$ & 36 & 33041 & .106 & .308 \\
\hline Educ6 & $=1$ if incomplete secondary education & 36 & 33041 & .169 & .374 \\
\hline Educ7 & $=1$ if complete secondary education & 36 & 33041 & .091 & .287 \\
\hline Educ8 & $=1$ if university education & 36 & 33041 & .148 & .355 \\
\hline Income1 & $=1$ if bottom income quintile & 36 & 33041 & .199 & .399 \\
\hline Income2 & $=1$ if second income quintile & 36 & 33041 & .289 & .453 \\
\hline Income3 & $=1$ if third income quintile & 36 & 33041 & .255 & .436 \\
\hline Income4 & $=1$ if fourth income quintile & 36 & 33041 & .162 & .368 \\
\hline Income5 & $=1$ if highest income quintile & 36 & 33041 & .093 & .290 \\
\hline
\end{tabular}


Table 2: Two-sample Tests of Proportions

\begin{tabular}{|l|c|c|c|}
\hline & Low Income Country - High Income Country & z-statistic & p-value \\
\hline TAX & $.154-.132=.022$ & 5.43 & $<.01$ \\
\hline PROTECTION & $.535-.550=-.015$ & -1.77 & .077 \\
\hline BELONG & $.061-.084=-.023$ & -8.03 & $<.01$ \\
\hline WORK & $.053-.031=.022$ & 9.84 & $<.01$ \\
\hline
\end{tabular}


Table 3: Random Effects Probit Models (Basic Models)

(Standard errors in parentheses)

\begin{tabular}{|c|c|c|c|c|}
\hline & TAX & PROTECTION & BELONG & WORK \\
\hline \multirow[t]{2}{*}{ TAX } & & & 0.312 & 0.252 \\
\hline & & & $(0.031)^{* * *}$ & $(0.036) * * *$ \\
\hline \multirow[t]{2}{*}{ Age } & 0.000 & 0.000 & 0.002 & -0.001 \\
\hline & $(0.001)$ & $(0.001)$ & $(0.001)^{* *}$ & $(0.001)$ \\
\hline \multirow[t]{2}{*}{ Male } & 0.031 & 0.008 & -0.029 & 0.079 \\
\hline & $(0.019)^{*}$ & $(0.024)$ & $(0.024)$ & $(0.029) * * *$ \\
\hline \multirow[t]{2}{*}{ POLITICAL } & 0.105 & 0.061 & 0.097 & 0.097 \\
\hline & $(0.009)^{* * *}$ & $(0.012)^{* * *}$ & $(0.010)^{* * *}$ & $(0.013)^{* * *}$ \\
\hline \multirow[t]{2}{*}{ CIVIC } & 0.065 & 0.041 & -0.014 & -0.009 \\
\hline & $(0.007)^{* * *}$ & $(0.008)^{* * *}$ & $(0.009)$ & $(0.011)$ \\
\hline \multirow[t]{2}{*}{ Educ2 } & -0.089 & 0.036 & 0.029 & -0.066 \\
\hline & $(0.046) *$ & $(0.048)$ & $(0.060)$ & $(0.072)$ \\
\hline \multirow[t]{2}{*}{ Educ3 } & 0.025 & 0.158 & 0.019 & 0.045 \\
\hline & $(0.048)$ & $(0.061)^{* * *}$ & $(0.062)$ & $(0.074)$ \\
\hline \multirow[t]{2}{*}{ Educ4 } & 0.041 & 0.228 & 0.033 & 0.030 \\
\hline & $(0.045)$ & $(0.047) * * *$ & $(0.061)$ & $(0.072)$ \\
\hline \multirow[t]{2}{*}{ Educ5 } & 0.082 & 0.172 & 0.100 & 0.043 \\
\hline & $(0.050)$ & $(0.056)^{* * *}$ & $(0.066)$ & $(0.076)$ \\
\hline \multirow[t]{2}{*}{ Educ6 } & 0.124 & 0.295 & 0.142 & 0.133 \\
\hline & $(0.045)^{* * *}$ & $(0.049) * * *$ & $(0.060)^{* *}$ & $(0.069)^{*}$ \\
\hline \multirow[t]{2}{*}{ Educ7 } & 0.134 & 0.295 & 0.194 & 0.208 \\
\hline & $(0.049)^{* * *}$ & $(0.055)^{* * *}$ & $(0.063)^{* * *}$ & $(0.074)^{* * *}$ \\
\hline \multirow[t]{2}{*}{ Educ8 } & 0.194 & 0.414 & 0.302 & 0.314 \\
\hline & $(0.045)^{* * *}$ & $(0.049) * * *$ & $(0.060)^{* * *}$ & $(0.069)^{* * *}$ \\
\hline \multirow[t]{2}{*}{ Income1 } & 0.006 & 0.022 & -0.277 & -0.226 \\
\hline & $(0.039)$ & $(0.050)$ & $(0.049) * * *$ & $(0.061)^{* * *}$ \\
\hline \multirow[t]{2}{*}{ Income2 } & -0.087 & -0.121 & -0.231 & -0.294 \\
\hline & $(0.037)^{* *}$ & $(0.047)^{* *}$ & $(0.043)^{* * *}$ & $(0.056)^{* * *}$ \\
\hline \multirow[t]{2}{*}{ Income3 } & -0.062 & -0.016 & -0.054 & -0.148 \\
\hline & $(0.036)^{*}$ & $(0.046)$ & $(0.041)$ & $(0.054)^{* * *}$ \\
\hline \multirow[t]{2}{*}{ Income4 } & 0.011 & -0.005 & -0.025 & -0.074 \\
\hline & $(0.037)$ & $(0.049)$ & $(0.043)$ & $(0.055)$ \\
\hline \multirow[t]{2}{*}{ Constant } & -1.472 & -0.380 & -1.668 & -1.672 \\
\hline & $(0.066)^{* * *}$ & $(0.082) * * *$ & $(0.083)^{* * *}$ & $(0.102)^{* * *}$ \\
\hline Observations & 29500 & 23207 & 29500 & 29500 \\
\hline Countries & 33 & 24 & 33 & 33 \\
\hline
\end{tabular}

* significant at $10 \%$; $*$ significant at $5 \%$; *** significant at $1 \%$, includes size of town dummies 
Table 4: Partial Effects on Attitudes*

[Means of individual marginal effects are in square brackets]

\begin{tabular}{|c|c|c|}
\hline & $\partial \operatorname{Prob}(\mathrm{TAX}=1 \mid \mathbf{X})$ & $\partial$ Prob(PROTECTION $=1 \mid \mathbf{X})$ \\
\hline \multicolumn{3}{|l|}{$\begin{array}{l}\text { Panel A (basic } \\
\text { model) }\end{array}$} \\
\hline$\partial$ CIVIC & $\begin{array}{c}g(X b) *(.065) \\
{[.013]}\end{array}$ & $\begin{array}{c}g(X b) *(.041) \\
{[.016]}\end{array}$ \\
\hline \multicolumn{3}{|l|}{$\begin{array}{l}\text { Panel B } \\
\text { (model with } \\
\text { GDP) }\end{array}$} \\
\hline$\partial$ CIVIC & $\begin{array}{c}g(X b) *(.111-.005 * \mathrm{GDP}) \\
{[.012]}\end{array}$ & $\begin{array}{c}g(X b) *(.327-.035 * \mathrm{GDP}) \\
{[.014]}\end{array}$ \\
\hline$\partial \mathrm{GDP}$ & Statistically Insignificant & $\begin{array}{c}g(X b) *(.189- \\
.035 * \text { CIVIC }+\beta * \text { INCOME }) \\
{[.059]}\end{array}$ \\
\hline \multicolumn{3}{|l|}{$\begin{array}{l}\text { Panel C } \\
\text { (model with } \\
\text { Energy } \\
\text { intensity) } \\
\end{array}$} \\
\hline$\partial$ CIVIC & $\begin{array}{c}g(X b) *(.083-.137 * \text { ENERGY }+.158 * \\
\text { ENERGY }) \\
{[.014]}\end{array}$ & $\begin{array}{c}g(X b) *(.10-.509 * \text { ENERGY }+ \\
\left..79 * \text { ENERGY }^{2}+\beta * \text { INCOME }\right) \\
{[.019]}\end{array}$ \\
\hline$\partial$ ENERGY & $\begin{array}{c}g(X b) *(-2.58+4.3 * \text { ENERGY- } \\
.14 * \text { CIVIC }+.32 * \text { ENERGY*CIVIC }+\beta * \text { INCOME }) \\
{[-.27]}\end{array}$ & $\begin{array}{c}g(X b) *(1.36-3.2 * \text { ENERGY- } \\
.51 * \text { CIVIC+1.58*ENERGY*CIVIC }+ \\
\left.\beta^{*} \text { INCOME }\right) \\
{[.11]}\end{array}$ \\
\hline
\end{tabular}

*Statistically significant coefficients in bold. INCOME is a vector including INCOME1, INCOME2, INCOME3, INCOME4. In most cases, the coefficients on the interactions of GDP and ENERGY with INCOME were insignificant, however, we did include these coefficients in the calculations of the marginal effects. See Appendix Tables 1-2 for the full set of coefficients from these estimations. 
Table 5: Partial Effects on Behaviors*

[Means of individual marginal effects are in square brackets.]

\begin{tabular}{|c|c|c|}
\hline & $\partial \operatorname{Prob}(\mathrm{BELONG}=1 \mid \mathbf{X})$ & $\partial \operatorname{Prob}($ WORK $=1 \mid \mathbf{X})$ \\
\hline \multicolumn{3}{|l|}{ Panel A (basic model) } \\
\hline$\partial$ CIVIC & Statistically Insignificant & Statistically Insignificant \\
\hline$\partial \mathrm{TAX}$ & $\begin{array}{c}g(X b) * .312 \\
{[.037]}\end{array}$ & $\begin{array}{c}g(X b) * .252 \\
{[.022]}\end{array}$ \\
\hline \multicolumn{3}{|l|}{$\begin{array}{l}\text { Panel B (model with } \\
\text { GDP) }\end{array}$} \\
\hline$\partial$ CIVIC & Statistically Insignificant & Statistically Insignificant \\
\hline$\partial \mathrm{TAX}$ & $\begin{array}{c}g(X b) * .308 \\
{[.033]}\end{array}$ & $\begin{array}{c}g(X b) * .259 \\
{[.025]}\end{array}$ \\
\hline$\partial \mathrm{GDP}$ & $\begin{array}{c}g(X b) *(-. \mathbf{1 0 2}+.005 * \mathrm{CIVIC}+ \\
\beta * \mathrm{INCOME}) \\
{[-.011]}\end{array}$ & $\begin{array}{c}g(X b) *(-.261+.003 * \text { CIVIC }+\beta * \text { INCOME }) \\
{[-.036]}\end{array}$ \\
\hline \multicolumn{3}{|l|}{$\begin{array}{l}\text { Panel C (model with } \\
\text { Energy intensity) }\end{array}$} \\
\hline$\partial \mathrm{CIVIC}$ & $\begin{array}{c}g(X b) *(.136-.800 * E N E R G Y+ \\
\left..750 * E^{2} E R G Y^{2}\right) \\
{[.0003]}\end{array}$ & $\begin{array}{c}g(X b) *(.228-1.438 * \text { ENERGY }+ \\
\left.1.532 * \mathrm{ENERGY}^{2}\right) \\
{[.0004]}\end{array}$ \\
\hline$\partial \mathrm{TAX}$ & $\begin{array}{c}g(X b) * .312 \\
{[.036]}\end{array}$ & $\begin{array}{c}g(X b) * .270 \\
{[.021]}\end{array}$ \\
\hline$\partial$ ENERGY & $\begin{array}{c}g(X b) *(1.037-.800 * \text { CIVIC }- \\
\text { 4.928*ENERGY }+ \\
\mathbf{1 . 5 0} * \text { CIVIC*ENERGY }+\beta * \text { INCOME }) \\
{[-.148]}\end{array}$ & $\begin{array}{c}g(X b) *(0.325-\mathbf{1 . 4 3 8} * \text { CIVIC }- \\
3.732 * \text { ENERGY }+ \\
\text { 3.064*CIVIC*ENERGY }+\beta * \text { INCOME }) \\
{[-.166]}\end{array}$ \\
\hline
\end{tabular}

*Statistically significant coefficients in bold. INCOME is a vector including INCOME1, INCOME2, INCOME3, INCOME4. In most cases, the coefficients on the interactions of GDP and ENERGY with INCOME were insignificant, however, we did include these coefficients in the calculation of the marginal effects. See Appendix Tables 1-2 for the full set of coefficients from these estimations. 
Table 6: Random Effects Probit Models with TRUST (Basic Models)

(Standard errors in parentheses)

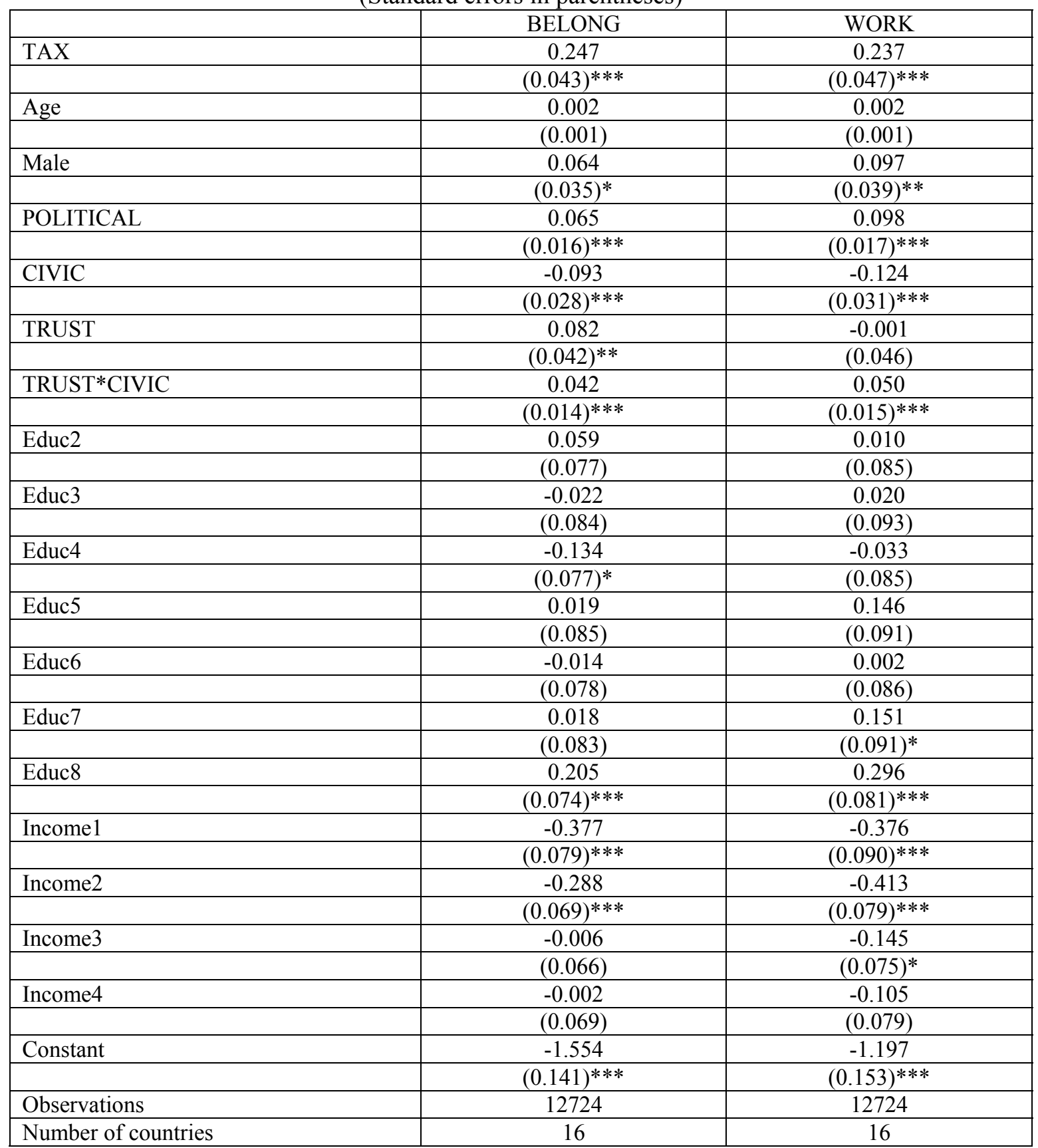

* significant at $10 \%$; ** significant at $5 \%$; ** significant at $1 \%$, includes size of town dummies 


\section{Appendix}

Table 1: Random Effects Probit Models with GDP

(Standard errors in parentheses)

\begin{tabular}{|c|c|c|c|c|}
\hline & TAX & PROTECTION & BELONG & WORK \\
\hline \multirow[t]{2}{*}{ TAX } & & & 0.312 & 0.252 \\
\hline & & & $(0.031)^{* * *}$ & $(0.036)^{* * *}$ \\
\hline \multirow[t]{2}{*}{ Age } & -0.000 & -0.000 & 0.001 & -0.000 \\
\hline & $(0.001)$ & $(0.001)$ & $(0.001)$ & $(0.001)$ \\
\hline \multirow[t]{2}{*}{ Male } & 0.036 & -0.036 & -0.038 & 0.071 \\
\hline & $(0.020)^{*}$ & $(0.024)$ & $(0.025)$ & $(0.030)^{* *}$ \\
\hline \multirow[t]{2}{*}{ POLITICAL } & 0.118 & 0.089 & 0.099 & 0.096 \\
\hline & $(0.009)^{* * *}$ & $(0.014)^{* * *}$ & $(0.011)^{* * *}$ & $(0.013)^{* * *}$ \\
\hline \multirow[t]{2}{*}{ CIVIC } & 0.111 & 0.327 & -0.046 & -0.053 \\
\hline & $(0.066)^{*}$ & $(0.081)^{* * *}$ & $(0.077)$ & $(0.087)$ \\
\hline \multirow[t]{2}{*}{ GDP } & -0.065 & 0.189 & -0.102 & -0.261 \\
\hline & $(0.047)$ & $(0.062) * * *$ & $(0.056)^{*}$ & $(0.069)^{* * *}$ \\
\hline \multirow[t]{2}{*}{ GDP*CIVIC } & -0.005 & -0.035 & 0.005 & 0.003 \\
\hline & $(0.007)$ & $(0.009)^{* * *}$ & $(0.008)$ & $(0.010)$ \\
\hline \multirow[t]{2}{*}{ Educ2 } & -0.101 & 0.049 & 0.009 & -0.039 \\
\hline & $(0.048)^{* *}$ & $(0.049)$ & $(0.063)$ & $(0.073)$ \\
\hline \multirow[t]{2}{*}{ Educ3 } & 0.012 & 0.134 & 0.015 & 0.033 \\
\hline & $(0.050)$ & $(0.062)^{* *}$ & $(0.064)$ & $(0.076)$ \\
\hline \multirow[t]{2}{*}{ Educ4 } & -0.002 & 0.200 & 0.038 & 0.043 \\
\hline & $(0.048)$ & $(0.050)^{* * *}$ & $(0.064)$ & $(0.074)$ \\
\hline \multirow[t]{2}{*}{ Educ5 } & 0.048 & 0.142 & 0.060 & 0.063 \\
\hline & $(0.051)$ & $(0.055)^{* *}$ & $(0.068)$ & $(0.077)$ \\
\hline \multirow[t]{2}{*}{ Educ6 } & 0.061 & 0.248 & 0.134 & 0.131 \\
\hline & $(0.047)$ & $(0.050)^{* * *}$ & $(0.064)^{* *}$ & $(0.072)^{*}$ \\
\hline \multirow[t]{2}{*}{ Educ7 } & 0.122 & 0.250 & 0.183 & 0.225 \\
\hline & $(0.051)^{* *}$ & $(0.055)^{* * *}$ & $(0.066) * * *$ & $(0.075)^{* * *}$ \\
\hline \multirow[t]{2}{*}{ Educ8 } & 0.144 & 0.394 & 0.289 & 0.287 \\
\hline & $(0.048)^{* * *}$ & $(0.051)^{* * *}$ & $(0.062)^{* * *}$ & $(0.071)^{* * *}$ \\
\hline \multirow[t]{2}{*}{ Income1 } & -0.211 & -0.027 & -0.531 & -0.531 \\
\hline & $(0.483)$ & $(0.589)$ & $(0.595)$ & $(0.648)$ \\
\hline \multirow[t]{2}{*}{ Income2 } & -0.163 & -1.291 & -1.003 & -1.082 \\
\hline & $(0.454)$ & $(0.560)^{* *}$ & $(0.538)^{*}$ & $(0.608)^{*}$ \\
\hline \multirow[t]{2}{*}{ Income3 } & 0.164 & -0.790 & -0.125 & 0.320 \\
\hline & $(0.452)$ & $(0.554)$ & $(0.530)$ & $(0.601)$ \\
\hline \multirow[t]{2}{*}{ Income4 } & 0.345 & 0.005 & -0.196 & -0.175 \\
\hline & $(0.475)$ & $(0.587)$ & $(0.553)$ & $(0.617)$ \\
\hline \multirow[t]{2}{*}{ Income1GDP } & 0.026 & 0.008 & 0.025 & 0.032 \\
\hline & $(0.050)$ & $(0.065)$ & $(0.061)$ & $(0.067)$ \\
\hline \multirow[t]{2}{*}{ Income2GDP } & 0.011 & 0.139 & 0.081 & 0.089 \\
\hline & $(0.047)$ & $(0.062)^{* *}$ & $(0.055)$ & $(0.063)$ \\
\hline \multirow[t]{2}{*}{ Income3GDP } & -0.021 & 0.088 & 0.002 & -0.052 \\
\hline & $(0.047)$ & $(0.061)$ & $(0.054)$ & $(0.063)$ \\
\hline \multirow[t]{2}{*}{ Income4GDP } & -0.033 & -0.001 & 0.016 & 0.013 \\
\hline & $(0.049)$ & $(0.065)$ & $(0.056)$ & $(0.064)$ \\
\hline Observations & 27337 & 21050 & 27337 & 27337 \\
\hline Countries & 30 & 21 & 30 & 30 \\
\hline
\end{tabular}

$*$ significant at 10\%; ** significant at 5\%; *** significant at 1\%, includes size of town dummies 
Appendix Table 2: Random Effects Probit Models with Energy Intensity (Standard errors in parentheses)

\begin{tabular}{|c|c|c|c|c|}
\hline & TAX & PROTECTION & BELONG & WORK \\
\hline \multirow{2}{*}{ TAX } & & & 0.312 & 0.270 \\
\hline & & & $(0.032)^{* * *}$ & $(0.038)^{* * *}$ \\
\hline \multirow[t]{2}{*}{ Age } & 0.000 & -0.001 & 0.002 & -0.001 \\
\hline & $(0.001)$ & $(0.001)$ & $(0.001)^{* * *}$ & $(0.001)$ \\
\hline \multirow[t]{2}{*}{ Male } & 0.031 & -0.063 & -0.035 & 0.086 \\
\hline & $(0.020)$ & $(0.025)^{* * *}$ & $(0.025)$ & $(0.031)^{* * *}$ \\
\hline \multirow[t]{2}{*}{ POLITICAL } & 0.116 & 0.084 & 0.102 & 0.090 \\
\hline & $(0.009)^{* * *}$ & $(0.014) * * *$ & $(0.011)^{* * *}$ & $(0.014)^{* * *}$ \\
\hline \multirow{2}{*}{ CIVIC } & 0.083 & 0.102 & 0.136 & 0.228 \\
\hline & $(0.035)^{* *}$ & $(0.050)^{* *}$ & $(0.043)^{* * *}$ & $(0.051)^{* * *}$ \\
\hline \multirow{2}{*}{ ENERGY } & -2.579 & 1.362 & 1.037 & 0.325 \\
\hline & $(0.683)^{* * *}$ & $(0.969)$ & $(0.949)$ & $(1.170)$ \\
\hline \multirow{2}{*}{ ENERGY*CIVIC } & -0.137 & -0.509 & -0.800 & -1.438 \\
\hline & $(0.213)$ & $(0.311)$ & $(0.271)^{* * *}$ & $(0.324)^{* * *}$ \\
\hline \multirow{2}{*}{ ENERGY $^{2}$} & 2.148 & -1.605 & -2.464 & -1.866 \\
\hline & $(0.730)^{* * *}$ & $(1.044)$ & $(1.072)^{* *}$ & $(1.304)$ \\
\hline \multirow[t]{2}{*}{ ENERGY $^{2 *}$ CIVIC } & 0.158 & 0.791 & 0.750 & 1.532 \\
\hline & $(0.236)$ & $(0.387)^{* *}$ & $(0.329)^{* *}$ & $(0.390)^{* * *}$ \\
\hline \multirow{2}{*}{ Educ2 } & -0.111 & 0.040 & 0.008 & -0.100 \\
\hline & $(0.048)^{* *}$ & $(0.050)$ & $(0.062)$ & $(0.078)$ \\
\hline \multirow[t]{2}{*}{ Educ3 } & 0.046 & 0.081 & 0.014 & -0.001 \\
\hline & $(0.050)$ & $(0.063)$ & $(0.064)$ & $(0.083)$ \\
\hline \multirow[t]{2}{*}{ Educ4 } & 0.060 & 0.176 & 0.037 & 0.038 \\
\hline & $(0.048)$ & $(0.050)^{* * *}$ & $(0.063)$ & $(0.080)$ \\
\hline \multirow[t]{2}{*}{ Educ5 } & 0.038 & 0.119 & 0.098 & 0.040 \\
\hline & $(0.052)$ & $(0.057)^{* *}$ & $(0.067)$ & $(0.080)$ \\
\hline \multirow[t]{2}{*}{ Educ6 } & 0.079 & 0.225 & 0.168 & 0.118 \\
\hline & $(0.048)$ & $(0.052)^{* * *}$ & $(0.062) * * *$ & $(0.075)$ \\
\hline \multirow[t]{2}{*}{ Educ7 } & 0.112 & 0.250 & 0.178 & 0.193 \\
\hline & $(0.052)^{* *}$ & $(0.057)^{* * *}$ & $(0.065)^{* * *}$ & $(0.078)^{* *}$ \\
\hline \multirow[t]{2}{*}{ Educ8 } & 0.172 & 0.395 & 0.300 & 0.290 \\
\hline & $(0.049)^{* * *}$ & $(0.053)^{* * *}$ & $(0.062) * * *$ & $(0.073)^{* * *}$ \\
\hline \multirow[t]{2}{*}{ Income1 } & -0.041 & -0.107 & -0.272 & -0.333 \\
\hline & $(0.078)$ & $(0.156)$ & $(0.114)^{* *}$ & $(0.139)^{* *}$ \\
\hline \multirow[t]{2}{*}{ Income2 } & -0.195 & -0.128 & -0.284 & -0.484 \\
\hline & $(0.073)^{* * *}$ & $(0.150)$ & $(0.100)^{* * *}$ & $(0.127)^{* * *}$ \\
\hline \multirow[t]{2}{*}{ Income3 } & -0.239 & -0.036 & 0.001 & -0.051 \\
\hline & $(0.072)^{* * *}$ & $(0.150)$ & $(0.098)$ & $(0.127)$ \\
\hline \multirow[t]{2}{*}{ Income4 } & -0.067 & -0.035 & -0.000 & -0.149 \\
\hline & $(0.076)$ & $(0.161)$ & $(0.104)$ & $(0.130)$ \\
\hline \multirow[t]{2}{*}{ Income1Energy } & 0.180 & 0.424 & 0.071 & 0.554 \\
\hline & $(0.231)$ & $(0.535)$ & $(0.412)$ & $(0.499)$ \\
\hline Income2Energy & 0.312 & 0.069 & 0.233 & 0.966 \\
\hline & $(0.223)$ & $(0.521)$ & $(0.374)$ & $(0.466)^{* *}$ \\
\hline Income3Energy & 0.634 & -0.024 & -0.224 & -0.207 \\
\hline & $(0.221)^{* * *}$ & $(0.524)$ & $(0.371)$ & $(0.481)$ \\
\hline Income4Energy & 0.263 & 0.082 & -0.116 & 0.418 \\
\hline & $(0.239)$ & $(0.564)$ & $(0.398)$ & $(0.489)$ \\
\hline Observations & 26904 & 20615 & 26904 & 26904 \\
\hline Countries & 29 & 20 & 29 & 29 \\
\hline
\end{tabular}

significant at $10 \%$; $*$ significant at $5 \% ; * * *$ significant at $1 \%$, includes size of town dummies 
Appendix Table 3: Random Effects Probit Models with TRUST

(Standard errors in parentheses)

\begin{tabular}{|c|c|c|c|c|}
\hline & BELONG & WORK & BELONG & WORK \\
\hline \multirow[t]{2}{*}{ TAX } & 0.232 & 0.238 & 0.247 & 0.242 \\
\hline & $(0.045)^{* * *}$ & $(0.049)^{* * *}$ & $(0.047)^{* * *}$ & $(0.050)^{* * *}$ \\
\hline \multirow[t]{2}{*}{ Age } & 0.003 & 0.002 & 0.003 & 0.003 \\
\hline & $(0.001)^{* *}$ & $(0.001)$ & $(0.001)^{* *}$ & $(0.001)^{* *}$ \\
\hline \multirow[t]{2}{*}{ Male } & 0.028 & 0.088 & 0.041 & 0.094 \\
\hline & $(0.037)$ & $(0.041)^{* *}$ & $(0.038)$ & $(0.042)^{* *}$ \\
\hline \multirow[t]{2}{*}{ POLITICAL } & 0.078 & 0.091 & 0.080 & 0.101 \\
\hline & $(0.017) * * *$ & $(0.019) * * *$ & $(0.018) * * *$ & $(0.019) * * *$ \\
\hline \multirow[t]{2}{*}{ CIVIC } & -0.096 & -0.030 & 0.212 & 0.153 \\
\hline & $(0.104)$ & $(0.117)$ & $(0.071)^{* * *}$ & $(0.073)^{* *}$ \\
\hline \multirow[t]{2}{*}{ TRUST } & 0.062 & -0.005 & 0.044 & -0.026 \\
\hline & $(0.043)$ & $(0.047)$ & $(0.045)$ & $(0.048)$ \\
\hline \multirow[t]{2}{*}{ TRUST*CIVIC } & 0.043 & 0.054 & 0.052 & 0.059 \\
\hline & $(0.014) * * *$ & $(0.015) * * *$ & $(0.015)^{* * *}$ & $(0.016) * * *$ \\
\hline \multirow[t]{2}{*}{ GDP } & -0.130 & -0.210 & & \\
\hline & $(0.070)^{*}$ & $(0.077)^{* * *}$ & & \\
\hline \multirow[t]{2}{*}{ GDP*CIVIC } & -0.000 & -0.011 & & \\
\hline & $(0.011)$ & $(0.013)$ & & \\
\hline \multirow[t]{2}{*}{ ENERGY } & & & 3.826 & 1.744 \\
\hline & & & $(1.566)^{* *}$ & $(1.594)$ \\
\hline \multirow[t]{2}{*}{ ENERGY*CIVIC } & & & -1.999 & -1.893 \\
\hline & & & $(0.406) * * *$ & $(0.426) * * *$ \\
\hline \multirow[t]{2}{*}{ ENERGY $^{2}$} & & & -4.790 & -1.515 \\
\hline & & & $(1.647)^{* * *}$ & $(1.695)$ \\
\hline \multirow[t]{2}{*}{$\mathrm{ENERGY}^{2} * \mathrm{CIVIC}$} & & & 2.311 & 2.182 \\
\hline & & & $(0.523)^{* * *}$ & $(0.548) * * *$ \\
\hline \multirow[t]{2}{*}{ Educ2 } & 0.085 & 0.006 & 0.067 & 0.014 \\
\hline & $(0.079)$ & $(0.088)$ & $(0.081)$ & $(0.090)$ \\
\hline \multirow[t]{2}{*}{ Educ3 } & -0.006 & 0.065 & -0.019 & 0.058 \\
\hline & $(0.087)$ & $(0.097)$ & $(0.088)$ & $(0.096)$ \\
\hline \multirow[t]{2}{*}{ Educ4 } & -0.080 & 0.014 & -0.097 & 0.031 \\
\hline & $(0.080)$ & $(0.089)$ & $(0.084)$ & $(0.089)$ \\
\hline \multirow[t]{2}{*}{ Educ5 } & 0.036 & 0.124 & 0.032 & 0.165 \\
\hline & $(0.086)$ & $(0.093)$ & $(0.089)$ & $(0.094)^{*}$ \\
\hline \multirow[t]{2}{*}{ Educ6 } & 0.008 & 0.009 & 0.013 & 0.078 \\
\hline & $(0.080)$ & $(0.089)$ & $(0.082)$ & $(0.090)$ \\
\hline \multirow[t]{2}{*}{ Educ7 } & 0.064 & 0.123 & 0.044 & 0.172 \\
\hline & $(0.085)$ & $(0.093)$ & $(0.088)$ & $(0.095)^{*}$ \\
\hline \multirow[t]{2}{*}{ Educ8 } & 0.232 & 0.287 & 0.193 & 0.324 \\
\hline & $(0.076) * * *$ & $(0.083)^{* * *}$ & $(0.079)^{* *}$ & $(0.085) * * *$ \\
\hline Income1 & -0.491 & 0.134 & -0.332 & -0.282 \\
\hline & $(0.726)$ & $(0.798)$ & $(0.241)$ & $(0.253)$ \\
\hline Income 2 & -1.461 & -1.186 & -0.322 & -0.395 \\
\hline & $(0.651)^{* *}$ & $(0.711)^{*}$ & $(0.220)$ & $(0.231)^{*}$ \\
\hline Income3 & -0.563 & 0.263 & 0.164 & 0.255 \\
\hline & $(0.642)$ & $(0.707)$ & $(0.217)$ & $(0.229)$ \\
\hline Income4 & -0.547 & -0.229 & 0.087 & 0.073 \\
\hline & $(0.670)$ & $(0.726)$ & $(0.226)$ & $(0.239)$ \\
\hline Constant & -0.345 & 0.574 & -2.064 & -1.716 \\
\hline & $(0.669)$ & $(0.736)$ & $(0.339) * * *$ & $(0.337)^{* * *}$ \\
\hline Observations & 10774 & 10774 & 10371 & 10371 \\
\hline Number of countries & 13 & 13 & 12 & 12 \\
\hline
\end{tabular}

* significant at $10 \%$; ** significant at $5 \%$; $* *$ significant at $1 \%$, includes size of town dummies and interactions between Income and GDP or Income and Energy 
Appendix Table 4: Countries in Sample

(*Countries with observations for TRUST, "Trust in environmental movement")

\begin{tabular}{|c|c|}
\hline COUNTRY & OBSERVATIONS \\
\hline Albania* & 451 \\
\hline Algeria & 816 \\
\hline Austria & 1,106 \\
\hline Bangladesh* & 1,161 \\
\hline Belarus & 726 \\
\hline Belgium & 1,339 \\
\hline Bosnia* & 1,005 \\
\hline Canada* & 1,600 \\
\hline Chile* & 996 \\
\hline Croatia & 776 \\
\hline Czech Republic & 1,390 \\
\hline Denmark & 758 \\
\hline Finland & 771 \\
\hline France & 1,105 \\
\hline Germany & 1,298 \\
\hline Greece & 781 \\
\hline India & 1,382 \\
\hline Italy & 1,314 \\
\hline Lithuania & 511 \\
\hline Luxembourg & 519 \\
\hline Macedonia* & 578 \\
\hline Mexico* & 706 \\
\hline Moldova* & 578 \\
\hline Montenegro & 469 \\
\hline Morocco & 621 \\
\hline Netherlands & 901 \\
\hline Philippines* & 1,135 \\
\hline Puerto Rico* & 617 \\
\hline Russia & 1,806 \\
\hline Serbia & 794 \\
\hline Spain* & 656 \\
\hline Ukraine & 808 \\
\hline United Kingdom of Great Britain & 572 \\
\hline USA* & 1,046 \\
\hline Venezuela & 938 \\
\hline Viet Nam* & 760 \\
\hline Total & 33,041 \\
\hline
\end{tabular}

